\title{
Intercellular adhesion molecule-1 (ICAM-1) is upregulated on alveolar macrophages from AIDS patients
}

\author{
S. Bohnet, J. Braun, K. Dalhoff
}

\begin{abstract}
Intercellular adhesion molecule-1 (ICAM-1) is upregulated on alveolar macrophages from AIDS patients. S. Bohnet, J. Braun, K. Dalhoff. CERS Journals Ltd 1994.

ABSTRACT: In acquired immune deficiency syndrome (AIDS) patients, alveolar macrophages (AMs) have an increased ability to serve as accessory cells during the generation of an immune response. In addition to soluble mediators, like cytokines, molecules of the major histocompatibility complex (MHC) class II and adhesion molecules, like intercellular adhesion molecule-1 (ICAM-1), play a major role in the regulation of these cellular interactions.

Using an enzyme-linked immunosorbent assay (ELISA) technique and immunocytochemical staining, we investigated ICAM-1 and human leucocyte antigen-DR (HLA-DR) expression on AMs from 20 AIDS (HIV+) patients in context with other parameters of macrophage activation, such as tumour necrosis factor- $\alpha$ (TNF- $\alpha)$ secretion and the release of superoxide anion, comparing the results to a group of healthy volunteers. In addition, we quantified soluble ICAM-1 in the bronchoalveolar lavage fluid (BALF) using a commercially available kit.

We found a nearly twofold increase in ICAM-1 expression $(0.81 \pm 0.30$ (sD) versus $0.42 \pm 0.12$ ELISA units $($ EU) $($ mean \pm SD) $)$, whilst the number of HLA-DR+ AMs was slightly decreased in AIDS-patients $(80 \pm 5$ versus $89 \pm 3 \%)$. Furthermore, soluble ICAM-1 in the BALF of these patients was significantly increased $(41.9 \pm 26.1 \mathrm{ver}$ sus $\left.19.1 \pm 5.1 \mathrm{ng} \cdot \mathrm{ml}^{-1}\right)$. ICAM-1 levels on AMs in the patient group correlated strongly with the sodium fluoride triggered release of superoxide anion $\left(\mathrm{O}_{2}^{-}\right)$but not with the spontaneous secretion of TNF- $\alpha$ by AMs.

Considering the present knowledge of the role of oxygen radicals in virus replication, increased ICAM-1 expression might reflect the active state of HIV-1 infection of AM in advanced disease. Furthermore, enhanced adhesiveness may facilitate syncytia formation between macrophages and lymphocytes and, thereby, the transfer of HIV-1 to susceptible CD4+ cells, which will ultimately result in a CD4+ cell depletion of the pulmonary compartment.

Eur Respir J., 1994, 7, 229-234.
\end{abstract}

Dept of Internal Medicine, Medical University of Lübeck, Lübeck, Germany.

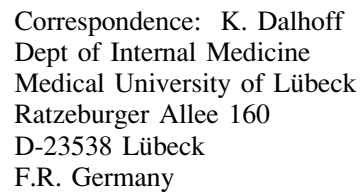

Keywords: Alveolar macrophage acquired immune deficiency syndrome human immunodeficiency virus-1 intercellular adhesion molecule-1 reactive oxygen species tumour necrosis factor- $\alpha$

Received: March 101993 Accepted after revision October 21993
Cells of the mononuclear phagocyte system represent the predominant cell population expressing human immunodeficiency virus-1 (HIV-1) in most tissues. Unlike CD4+ T-lymphocytes, monocytes and macrophages are relatively resistant to the cytopathic effect of HIV-1 and, thus, serve as a reservoir for the virus [1]. In the lung, alveolar macrophages (AMs) are the primary cell targets harbouring HIV-1 chronically. It is evident that AMs of acquired immune deficiency syndrome (AIDS) patients display a series of immunological abnormalities [2], which include inappropriate secretion of cytokines, such as interleukin-6 (IL-6) and tumour necrosis factor$\alpha$ (TNF- $\alpha)$ [3, 4]. In addition the ability of AMs to function as accessory cells (ACs) in T-cell responses seems to be altered. However, data available at present are controversial. In vitro infection of monocytes and monocyte-derived macrophages with HIV-1 leads to decreased $\mathrm{AC}$ function [5]. In contrast, alveolar macrop hages demonstrate enhanced AC function in HIV-1 infected patients in vivo [6], which is clinically reflected in the nonspecific alveolitis commonly present in these patients.

Effective macrophage/lymphocyte interaction requires direct cell-to-cell contact. Molecules of the major histocompatibility complex (MHC) class II represent one group of receptors on the antigen presenting cell (APC), which contribute to the physical interaction of APCs and lymphocytes. In addition, adhesion molecules, like ICAM1 and its ligands CD11a/CD18 and CD11b/CD18, enhance the interaction between APCs and lymphocytes, thus providing important co-stimulatory signals to T-cell proliferation [7]. ICAM-1, a member of the immunoglobulin $\mathrm{G}$ (IgG) gene superfamily, is a cytokine-inducible adhesion molecule which can be expressed on a variety of cells during inflammation. It has previously been demonstrated, that alveolar macrophages and bronchial epithelial cells express ICAM-1 in active sarcoidosis and asthma [8, 9].

The aim of the present study was to determine whether AMs from AIDS patients, who present with pulmonary 
inflammation of completely different pathophysiology, demonstrate altered expression of adhesion molecules. We investigated ICAM-1 and human leucocyte antigenDR (HLA-DR) expression on AMs in a group of patients with AIDS. Our data indicate that ICAM-1 is markedly upregulated on AMs whilst the number of HLA-DR+ AMs was decreased in AIDS patients as compared to healthy volunteers.

\section{Patients and methods}

\section{Patients}

Twenty patients (17 males and 3 females), aged 27-62 yrs (mean 38 yrs), with seropositive HIV-1 infection were studied. Six patients were smokers. Mean peripheral blood CD4-count at the time of bronchoalveolar lavage (BAL) was 59· $\mathrm{ll}^{-1}$ (range 5-300 cells $\cdot \mu \mathrm{l}^{-1}$ ); p24 antigen could be detected in the serum of all but one patient (mean $115 \mathrm{pg} \cdot \mathrm{ml}^{-1}$, range $0-300 \mathrm{pg} \cdot \mathrm{ml}^{-1}$ ). All patients belonged to the group IV of the Center for Disease Control (CDC) classification (IVa: $n=4$; IVc: $n=12 ;$ IVd: $n=2$, IVc+d: $n=2)$. For the purposes of this study patients were classified to have AIDS according to the new definition of the Desease Control when either the blood CD4-count was below 200 per $\mathrm{ml}$ and/or AIDS-defining events had occured. Fifteen out of twenty patients received antiretroviral therapy with zidovudine (AZT) or didanosine (DDI). BAL was performed to obtain or exclude a specific diagnosis of opportunistic pulmonary infection and/or AIDS-related tumours. According to the declaration of Helsinki, this invasive procedure is performed only for diagnostic purposes. Six healthy nonsmoking male volunteers were accepted as controls.

\section{Methods}

Bronchoalveolar lavage was performed with a flexible fibrescope under standard conditions [10]. Briefly, a total of $200 \mathrm{ml}$ of saline solution was injected in $20 \mathrm{ml}$ aliquots with immediate vacuum aspiration after each aliquot. Mean recovery was $75 \%$ in patients and control subjects. The first $20 \mathrm{ml}$ aliquot, which is known to be contaminated by bronchial secretions, was discarded. Another sample was used for microbiological evaluation (quantitative bacterial cultures, mycobacterial and fungal cultures, immunofluorescence stains for Pneumocystis carinii) and remaining portions were pooled.

After enumeration of total cell count on a haemocytometer (Neubauer), lavage cell differentials were determined by Wright-Giemsa stains of cytocentrifuge preparations (Cytospin II, Shandon). Cell viability was assessed using trypan blue dye exclusion. Lavage cells were washed twice using phosphate buffered saline (PBS) $\left(0.1 \mathrm{~mol} \cdot l^{-1}, \mathrm{pH} 7.2\right)$ and resuspended at a concentration of $1 \times 10^{6}$ viable $\mathrm{AM} \cdot \mathrm{ml}^{-1}$ in M199 supplemented with $5 \%$ foetal calf serum (FCS) and penicillin-streptomycin. All cell culture reagents were obtained from Gibco (Eggenstein, Germany). Endotoxin contamination was less than 25 $\mathrm{pg} \cdot \mathrm{ml}^{-1}$ (M199) or $100 \mathrm{pg} \cdot \mathrm{ml}^{-1}$ (FCS) as determined by the Limulus amebocyte lysate assay.

\section{Analysis}

ICAM-1. Lavage cells containing AMs at a density of $10^{6}$ cells $\cdot \mathrm{ml}^{-1}$ were seeded into 96 -well flat-bottomed microtitre plates $\left(100 \mu \mathrm{l} \cdot \mathrm{well}^{-1}\right)$ for $3 \mathrm{~h}$ at $37^{\circ} \mathrm{C}$, allowing the macrophages to adhere. Nonadherent cells were removed by gentle washing with warm cell culture medium. The resulting adherent cell population was composed of more than $95 \%$ macrophages, as determined by nonspecific esterase staining.

ICAM-1 expression on AMs was determined using an enzyme-linked immunosorbent assay (ELISA) technique. Prior to each of the following steps, cells were washed three times with PBS $\left(0.1 \mathrm{~mol} \cdot l^{-1}, \mathrm{pH} 7.2\right)$. Cells were fixed with $1 \%$ paraformaldehyde for $30 \mathrm{~min}$ at room temperature and free binding sites were blocked by adding a $2 \%$ solution of bovine serum albumin (BSA) (Serva) diluted in PBS $\left(0.1 \mathrm{~mol} \cdot l^{-1}, \mathrm{pH} 7.2\right)$ for $45 \mathrm{~min}$ $\left(37^{\circ} \mathrm{C}\right)$. The monoclonal anti-ICAM-1 antibody (clone 84H10, Dianova, Hamburg, Germany, $1: 1,000$ in $0.1 \%$ BSA/PBS) was added for $2 \mathrm{~h}$. Peroxidase-conjugated goat anti-mouse IgG (Sigma, Deisenhofen, Germany, $1: 1,000$ in $0.1 \%$ BSA/PBS) was used as developing antibody for $1 \mathrm{~h}\left(37^{\circ} \mathrm{C}\right)$. Finally, 2,2'-azinobis (3-ethylbenzthiazolinesulphonic acid) (ABTS) (Sigma, $1 \mathrm{mg} \cdot \mathrm{ml}^{-1}$ ) and hydrogen peroxide $\left(2.8 \mu \mathrm{l} \cdot \mathrm{ml}^{-1} 30 \% \mathrm{H}_{2} \mathrm{O}_{2}\right)$ in $0.1 \mathrm{~mol} \cdot l^{-1}$ sodium acetate $(\mathrm{pH} 4.2)$ was added as substrate. The colour was allowed to develop for $120 \mathrm{~min}$ and plates were read with a microplate reader (Behring EL 311) at $405 \mathrm{~nm}$.

Results are expressed as ELISA units (EU) from quadruplicate wells after subtracting nonspecific background absorbance, which was determined in the absence of the primary antibody. The number of adherent cells at the end of each experiment was not different in patients and controls, as determined by crystal violet staining.

In addition, we determined soluble ICAM-1 in the BAL fluid using a commercially available kit (Serva, Heidelberg, Germany) according to the protocol provided.

MHC-class-II expression. For immunocytochemical staining, cytocentrifuge preparations of the lavage cells were dried at room temperature, wrapped in aluminium film and stored at $-20^{\circ} \mathrm{C}$ until use. Bronchoalveolar cells were characterized using a monoclonal anti-HLA-DR antibody (1:20, Dako Patts, Hamburg, Germany). Immunocytochemical staining was performed using the alkaline phosphatase monoclonal mouse antialkaline phosphatase (APAAP) method, as described previously [11]. In addition, we determined HLA-DR expression using the same ELISA method as described for the detection of ICAM-1 in a limited number of patients $(n=6)$. We found a significant correlation regarding detection of HLA-DR on AMs using these two methods ( $r=0.73$; $\mathrm{p}<0.05$ ). 
$T N F-\alpha$. Alveolar macrophages were seeded at a density of $10^{6}$ cells $\cdot \mathrm{ml}^{-1}$ in 96 -well flat bottomed microtitre plates, as described above. Supernatants from triplicate wells were removed after $24 \mathrm{~h}$, transferred to $1 \mathrm{ml}$ tubes and immediately frozen at $-20^{\circ} \mathrm{C}$ until use. TNF- $\alpha$ activity was assessed in a standard cytotoxicity assay using mouse L929 fibroblasts [12]. Briefly, $1.5 \times 10^{4}$ L929 cells were seeded into 96-well flat bottomed plates. Test samples were diluted threefold in series and added in duplicate to wells containing an equal volume of RPMI media with $5 \mu \mathrm{g} \cdot \mathrm{ml}^{-1}$ actinomycin D. Plates were incubated for $24 \mathrm{~h}$ at $37^{\circ} \mathrm{C}$ and remaining cells were fixed with $3 \%$ formaldehyde, stained with crystal violet and lysed in $0.5 \%$ sodium dodecyl sulphate (SDS). Optical density was read at $570 \mathrm{~nm}$ with a microplate reader (Behring EL 311). Serial dilutions of human recombinant TNF- $\alpha$ (5-500 U.ml-1 BASF Knoll AG) were used to produce a standard curve. The specificity of this bioassay was tested by neutralizing peak samples with a polyclonal rabbit anti-TNF- $\alpha$ antibody (British BioTechnology).

Superoxide anion. Superoxide generation of AMs was measured by the dismutase-inhibitable reduction of ferricytochrome c, according to the method of PICK [13]. Briefly, $10^{5} \mathrm{AMs}$ were incubated in triplicate wells of a 96-well flat bottomed microtitre plate in the presence of $100 \mu \mathrm{mol} \cdot l^{-1}$ of ferricytochrome $\mathrm{c} \pm 0.2$ $\mathrm{mg} \cdot \mathrm{ml}^{-1}$ superoxide dismutase (SOD) with or without 10 mmol $\cdot l^{-1} \mathrm{NaF}$. Optical density was determined at $550 \mathrm{~nm}$ over a period of $2 \mathrm{~h}$, in $30 \mathrm{~min}$ intervals, on a microplate reader.

\section{Statistics}

All results are expressed as mean \pm standard deviation. Nonparametric statistics were used throughout the study. The Mann Whitney U-test was used for independent samples, and the Wilcoxon signed rank test for paired samples. Correlations were made with the Spearman rank correlation. A p-value of $<0.05$ was considered significant [14].

\section{Results}

\section{$B A L$ findings and pulmonary diagnosis}

Table 1 summarizes the total and differential cell count of the BAL. Total cell recovery was significantly higher in AIDS patients. With regard to the differential count of BAL cells, the absolute number of AMs was increased in patients as compared to values in healthy volunteers. Final pulmonary diagnosis, as judged by the results of smears, cultures and histopathology, included Pneumocystis carinii pneumonia (PCP) in four of the patients, tuberculosis (TB) in one, pulmonary Kaposi's sarcoma (KS) in one, and bacterial pneumonia in three. (These patients were designated as having acute pul-
Table 1. - Lavage cell differentials of patients and healthy volunteers (controls)

\begin{tabular}{lccc}
\hline & $\begin{array}{c}\text { Patients } \\
\mathrm{n}=20\end{array}$ & $\begin{array}{c}\text { Controls } \\
\mathrm{n}=6\end{array}$ & $\mathrm{p}$ value \\
\hline Total cell recovery $\times 10^{6}$ & $19 \pm 12$ & $11 \pm 3$ & $<0.05$ \\
AMs $\times 10^{6}$ & $15.1 \pm 2.7$ & $9.9 \pm 0.8$ & $<0.05$ \\
Lymphocytes $\times 10^{6}$ & $1.7 \pm 1.3$ & $0.9 \pm 0.6$ & $\mathrm{NS}$ \\
Granulocytes $\times 10^{6}$ & $0.7 \pm 2.1$ & $0.1 \pm 0.1$ & $\mathrm{NS}$ \\
Eosinophils $\times 10^{6}$ & $0.1 \pm 0.1$ & $0 \pm 0.1$ & $\mathrm{NS}$ \\
\hline
\end{tabular}

Data are presented as mean \pm SD. AMs: alveolar macrophages; NS: nonsignificant.

monary inflammation). In eleven patients with fever of unknown origin and/or radiographic abnormalities on chest X-ray (e.g. peripheral consolidation), BAL revealed a nonspecific macrophage alveolitis without increase in lymphocytes or other inflammatory cells. (This group of patients was designated as being without acute pulmonary inflammation).

\section{ICAM-1 expression of AMs}

Figure 1 shows the ICAM-1 expression of AMs from patients and controls. ICAM-1 could be detected on the surface of AMs in all cases. However, ICAM-1 levels on AMs from patients with AIDS were significantly elevated $\left(0.81 \pm 0.30\right.$ versus $0.46 \pm 0.12 \mathrm{EU} \cdot 10^{-5}$ AMs; $\mathrm{p}<0.05)$. No difference could be demonstrated between the two patient subgroups presenting with or without

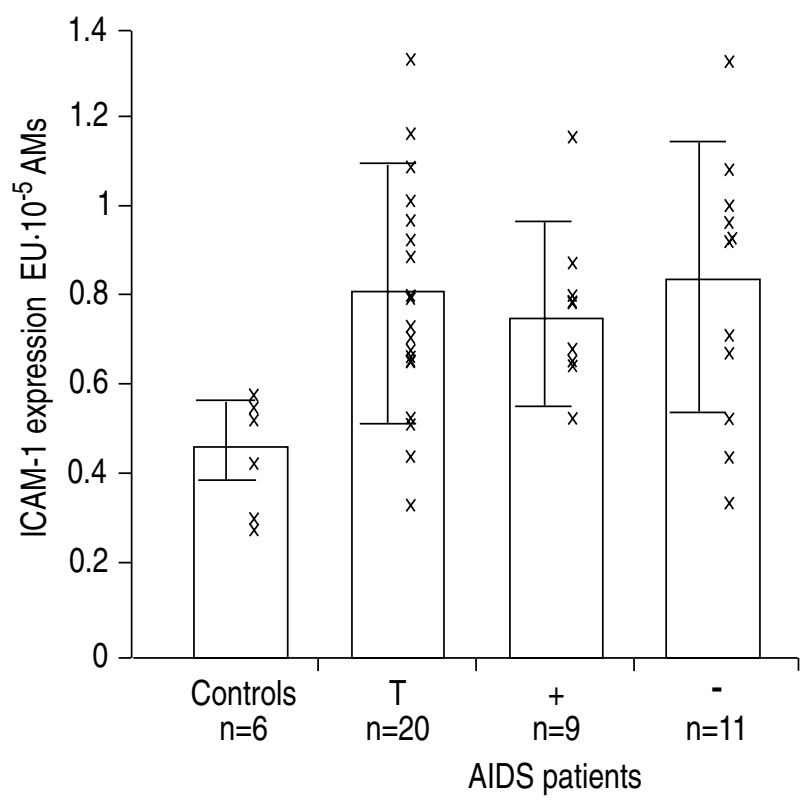

Fig. 1. - ICAM-1 expression of AMs from AIDS patients and healthy volunteers (controls) as quantified by ELISA. Mean, standard deviation and individuals values $(\mathrm{x}) . \mathrm{T}$ : total number of AIDS patients investigated; +: patients with acute pulmonary inflammation at the time of BAL; -: patients without acute pulmonary inflammation at the time of BAL; ICAM-1: intercellular adhesion molecule-1; EU: ELISA units; AMs: alveolar macrophages; AIDS: acquired immune deficiency syndrome; ELISA: enzyme-linked immunosorbent assay; BAL: bronchoalveolar lavage. 


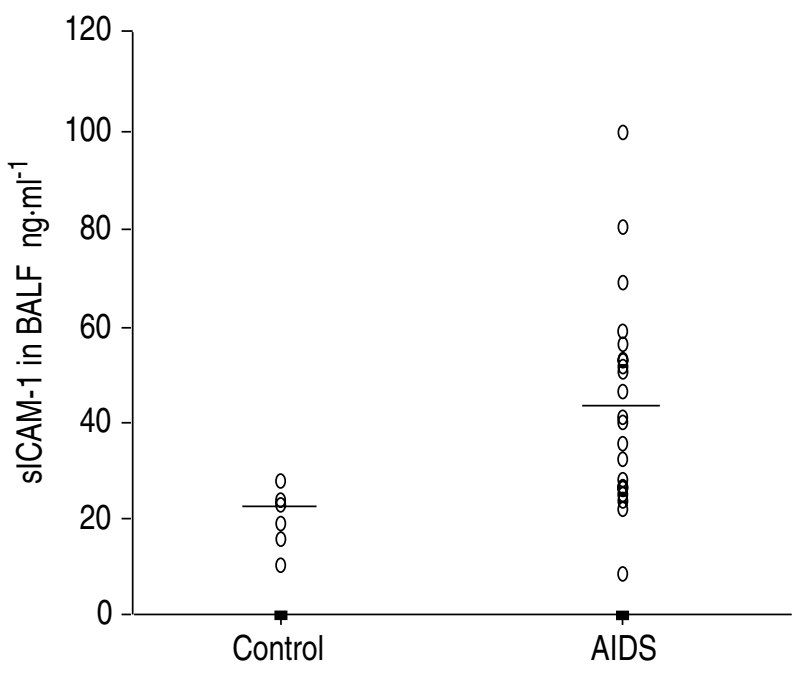

Fig. 2. - Soluble ICAM-1 (sICAM-1) levels in the bronchoalveolar lavage fluid (BALF) of AIDS patients and controls. Mean and individual values. For abbreviations see legend to figure 1 .

acute pulmonary inflammation at the time of BAL $\left(0.75 \pm 0.21\right.$ versus $\left.0.84 \pm 0.31 \mathrm{EU} \cdot 10^{-5} \mathrm{AMs} ; \mathrm{p}=\mathrm{NS}\right)$. In addition, ICAM-1 expression could be augmented by TNF- $\alpha\left(100 \mathrm{U} \cdot \mathrm{ml}^{-1}, 16 \mathrm{~h}, 37^{\circ} \mathrm{C}\right)$ on control AMs $(0.74 \pm 0.22$ EU; $\mathrm{p}<0.05)$, whereas AMs from AIDS patients were totally resistant to further stimulation by this cytokine, even at higher dosages (500 U.ml-1, data not shown). ICAM-1 levels were not related to the absolute numbers of cells and lymphocytes recovered from the pulmonary compartment or to arterial oxygen tension $\left(\mathrm{PaO}_{2}\right)$ at the time of BAL. No correlation could be established in our study group to the serum levels of p24 antigen or to the absolute peripheral CD4+ count.

Soluble(s) ICAM-1 could be detected in the lavage fluid of all AIDS patients and controls. We found significantly increased amounts of SICAM-1 in the BALF of patients as compared to healthy volunteers $(41.9 \pm 26.1$ versus $19.1 \pm 5.1 \mathrm{ng} \cdot \mathrm{ml}^{-1}$; $\mathrm{p}<0.05$, fig. 2 ), without correlation to ICAM-1 surface expression or other parameters of macrophage activation.

\section{MHC class II molecules}

The average number of HLA-DR+ AMs as determined by immunocytochemistry was $80 \pm 5 \%$ in patients and $89 \pm 3 \%$ in the control group. The decrease in HLA-DR+ AMs was statistically significant $(\mathrm{p}<0.05)$.

\section{Release of TNF- $\alpha$}

As expected, AMs from AIDS patients spontaneously released increased amounts of $\mathrm{TNF}-\alpha$, whereas only little TNF- $\alpha$ activity could be detected in the supernatants of control AMs (179 \pm 196 versus $10 \pm 4 \mathrm{U} \cdot \mathrm{ml}^{-1}$; $\left.\mathrm{p}<0.05\right)$. We could not demonstrate a correlation either to the expression of ICAM-1 (fig. 3a) or to the release of reactive oxygen species in patients and controls.

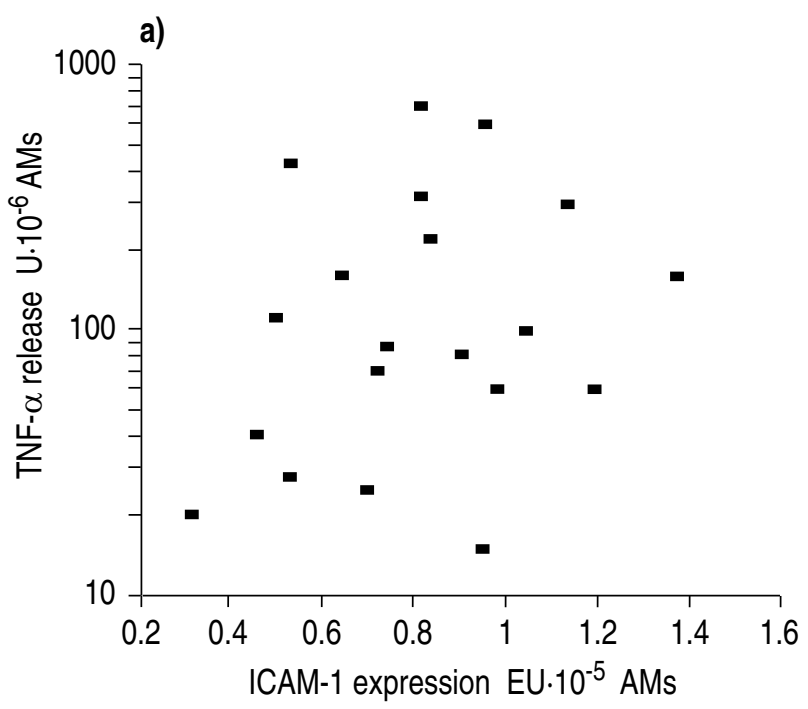

b)

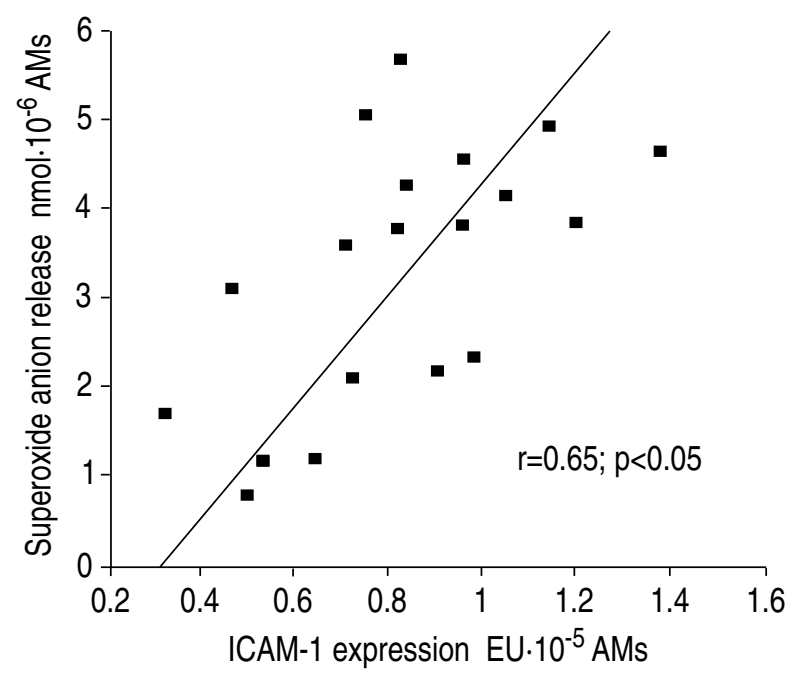

Fig. 3. - a) Relationship between ICAM-1 expression and the spontaneous release of TNF- $\alpha$ of AMs from AIDS patients. b) Correlation between ICAM-1 expression and the NaF-triggered release of superoxide anion of AMs from AIDS patients. TNF- $\alpha$ : tumour necrosis factor- $\alpha$. For further abbreviations see legend to figure 1 .

\section{Release of superoxide anion}

The spontaneous release of reactive oxygen species (ROS) by AMs was not statistically different in patients and healthy volunteers. Stimulation with $\mathrm{NaF}$ lead to a significantly increased release of superoxide anion in both groups $\left(3.16 \pm 1.54\right.$ versus $1.47 \pm 1.11 \mathrm{nmol} \cdot 10^{-6} \mathrm{AMs}$ in AIDS patients; $\mathrm{p}<0.002 ; 1.55 \pm 1.01$ versus $0.75 \pm 0.53$ $\mathrm{nmol} \cdot 10^{-6} \mathrm{AMs} ; \mathrm{p}<0.05$, in healthy volunteers). ICAM1 expression correlated strongly to the $\mathrm{NaF}$ stimulated release of superoxide anion in the patient group $(r=0.65$; $\mathrm{p}<0.05$ ) (fig. $3 \mathrm{~b}$ ) but not in healthy volunteers.

\section{Discussion}

The major finding of our study was that ICAM-1 expression on AMs from most patients with AIDS is 
markedly upregulated, whilst the number of HLA-DR+ cells was slightly decreased. Using an ELISA technique, we demonstrated an approximately twofold increase of ICAM-1 levels in the patients group as compared to healthy volunteers. Correspondingly, we found significantly increased amounts of shedded SICAM-1 in the lavage fluid of AIDS patients. No direct correlation between ICAM-1 expression on AMs and sICAM-1 could be established, which might be due to the fact that other cell types (e.g. epithelial cells) are probable contributors to the shedding of ICAM-1 in the bronchoalveolar lining fluid [9].

At present, only limited data are available on phenotypic characteristics of AMs in AIDS. Expression of ICAM-1 and other adhesion molecules has recently been detected by fluorescence-activated cell sorter (FACS) analysis [15]. There are several possible explanations for the increased ICAM-1 levels that we observed. It has been demonstrated previously that ICAM-1 expression can be upregulated by bacterial products, such as lipopolysaccharide (LPS) or S-fimbriae [16, 17]. Although we did not isolate Gram-negative bacteria using quantitative lavage cultures, we cannot completely exclude the possibility that small amounts of inhaled microbial antigens contribute to the upregulation of ICAM-1 on AMs. However, ICAM-1 levels in our study population were uniformly high, regardless of the presence or absence of acute opportunistic infection at the time of BAL.

A second explanation for high ICAM-1 levels on AMs from AIDS patients could be stimulation by cytokines. We and others [4] have demonstrated increased secretion of bioactive TNF- $\alpha$, which is known to induce ICAM-1 expression on different cell types. Surprisingly, no direct correlation between ICAM-1 expression and TNF- $\alpha$ secretion could be established. However, we did not measure other cytokines (e.g. IL-1 $\beta$ ), which are released by activated macrophages of HIV-1 infected patients and will probably contribute to the marked increase of ICAM-1 expression, [16].

A third possible mechanism for the upregulation of ICAM-1 expression on AMs could be direct stimulation by the virus itself. There are few data available at present concerning the induction of adhesion molecules by viral proteins. Tosi et al. [18] showed that parainfluenza virus infection of human airway epithelium resulted in increased ICAM-1 expression [18]. In another study, Hu et al. [19] demonstrated that hepatitis-B virus Xprotein upregulates ICAM-1 transcription. Recent data suggest an impact of the cellular viral load on the expression of HLA-DR in HIV-1 infected individuals [20]. In this context, no studies are available on ICAM-1. In our study population, p24 antigen in the supernatants of AMs was quantified in only two patients. We are therefore unable, at the moment, to establish a relationship between the production of viral proteins and ICAM-1 levels of AMs.

Interestingly, we found a strong correlation between the NaF-triggered release of $\mathrm{O}_{2}^{-}$and ICAM-1 levels. Since activation of HIV-1 by oxidative stress has been reported and the cellular redox status is critically involved in the regulation of virus replication [21-23], increased
ICAM-1 expression might as well reflect the active state of HIV-1 infection of AMs in AIDS.

Considering the role of adhesion molecules during cell proliferation and activation, high ICAM-1 levels could play a key role in the pathogenesis of the nonspecific alveolitis commonly observed in AIDS patients. Furthermore, binding of ICAM-1 to its integrin-ligand lymphocyte function associated antigen-1 (LFA-1) provides a mechanism for direct cell-to-cell contact, thus facilitating syncytia formation between HIV-1 infected AMs and noninfected CD4+ cells [24]. In addition, induction of T-cell proliferation, which is dependent on cell-tocell contact as well as on secondary signals, like cytokines, enhances T-cell susceptibility to infection by free virus [25]. Both mechanisms contribute to the CD4+ cell depletion of the pulmonary compartment.

On the other hand, upregulated ICAM-1 expression on AMs might reflect, at least in part, an ongoing immune response to HIV-1. Efficient generation of cytotoxic CD8+ lymphocytes [26] requires physical interaction of APCs and lymphocytes. Since the expression of MHC class II molecules seems to be decreased on AMs, at least in patients with advanced disease, high ICAM-1 levels may provide a mechanism to regain the adhesive capacity of those cells.

In summary, our data suggest that the increased expression of ICAM-1 on AMs from AIDS patients reflects the activated state of those cells, supporting the concept that AMs are pivotal cells in the pathogenesis of HIVrelated lung inflammation. It remains to be elucidated whether high ICAM-1 levels accelerate virus replication or provide a protective mechanism against it in the course of HIV-1 infection.

Acknowledgement: The authors thank M. Losch for expert technical assistance.

\section{References}

1. Meltzer MS, Skillman DR, Hoover DL, et al. HIV and the immune system: macrophages and the humanimmunodeficiency virus. Immunology Today 1990; 11: 217- 223 .

2. Agostini C, Trentin L, Zambello R, Semenzato G. HIV1 and the lung. Infectivity, pathogenetic mechanisms, and cellular immune responses taking place in the lower respiratory tract. Am Rev Respir Dis 1993; 147: 10381049.

3. Breen EC, Rezai AR, Nakjima K, et al. Infection with HIV is associated with elevated IL-6 levels and production. J Immunol 1990; 144: 480-484.

4. Agostini C, Zambello R, Trentin L, et al. Alveolar macrophages from patients with AIDS and AIDS-related complex constitutively synthesize and release tumor necrosis factor. Am Rev Respir Dis 1991; 144: 195-202.

5. Petit AJC, Tersmette M, Terpstra FG, deGoede REY, vanLier RAW, Miedema F. Decreased accessory cell function by human monocytic cells after infection with HIV. J Immunol 1988; 140: 1485-1489.

6. Twigg HL III, Iwamoto GK, Soliman DM. Role of cytokines in alveolar macrophage accessory cell function in HIV-infected individuals. J Immunol 1992; 149: 1462-1469. 
7. Springer TA. Adhesion receptors of the immune system. Nature 1990; 346: 425-434.

8. Striz I, Wang YM, Kalaycioglu O, Costabel U. Expression of alveolar macrophage adhesion molecules in pulmonary sarcoidosis. Chest 1992; 102: 882886.

9. Wegner CD, Gundel RH, Reilly P, Haynes N, Letts G, Rothlein R. Intercellular adhesion molecule-1 (ICAM1) in the pathogenesis of asthma. Science 1990; 247: 456-459.

10. Crystal RG, Reynolds HY, Kalica AR. Bronchoalveolar lavage. Chest 1986; 90: 122-131.

11. Erber WN, Pinching AJ, Mason DY. Immunocytochemical detection of T- and B-cell populations in routine blood smears. Lancet 1984; i: 1042-1046.

12. Meager A, Leung H, Woolley J. Assays for tumor necrosis factor. Immunol Method 1989; 166: 1-17.

13. Pick E. Microassay for superoxide anion and hydrogen peroxide production and nitroblue tetrazolium reduction using an enzyme immunoassay microplate reader. Method Enzymol 1986; 132: 407-421.

14. Sachs L. Angewandte Statistik. Springer Verlag, Berlin, 1984; pp. 230-238.

15. Agostini C, Trentin L, Zambello R, et al. Alveolar macrophages from patients with HIV-1 infection express accessory molecules, activation markers, and release increased amounts of biological response modifiers. Chest 1993; 103: 108s-111s.

16. Figdor CD, van Kooyk Y. Regulation of cell adhesion. In: Harlan JM, Liu DY, eds. Adhesion: Its Role in Inflammatory Disease. New York, WH Fremann and Co., 1990; pp. 151-182.

17. Kreft B, Bohnet S, Carstensen O, Hacker J, Marre R. Differential expression of interleukin-6, intercellular adhesion molecule-1, and major histocompatibility complex class II molecules in renal carcinoma cells stimulated with S fimbriae of uropathogenic Escherichia coli. Infect Immun 1992; 61: 3060-3063.

18. Tosi MF, Stark JM, Hamedani A, Smith CW, Gruenert
DC, Huang YT. Intercellular adhesion molecule-1 (ICAM1)-dependent and ICAM-1-independent adhesive interactions between polymorphonuclear leukocytes and human airway epithelial cells infected with parainfluenza virus type 2. J Immunol 1992; 149: 3345-3349.

19. $\mathrm{Hu} \mathrm{KQ}, \mathrm{Yu} \mathrm{CH}$, Vierling JM. Upregulation of intercellular adhesion molecule-1 transcription by hepatitisB virus X-protein. Proc Natl Acad Sci USA 1992; 89: 11441-11445.

20. Bray DH, Squire SB, Kawana A, Johnson MA, Poulter LW. Antiretroviral treatment reverses HIV-induced reduction in the expression of surface antigens on alveolar macrophages in AIDS patients. Clin Exp Immunol 1993; 91: 13-17.

21. Israel N, Gougerot-Pocidalo MA, Aillet F, Virelizier JL. Redox status of cells influences constitutive or induced NF-kappa-B translocation and HIV long terminal repeat activity in human $\mathrm{T}$ and monocytic cell lines. J Immunol 1992; 149: 3386-3393.

22. Schreck R, Rieber P, Baeuerle PA. Reactive oxygen intermediates as apparently widely used messengers in the activation of the NF-kappa-B transcription factor and HIV. EMBO J 1991; 10: 2247-2250.

23. Legrand-Poels S, Pincemail VD, van de Vorst A, Pietta J. Activation of human immunodeficiency virus type-1 by oxidative stress. AIDS Res Hum Retrovir 1990; 6: 1389-1397.

24. Butini L, Pantaleo G, Vaccarezza M, et al. ICAM 1/2/3 molecules function as counterreceptors for LFA-1 in HIVmediated syncytia formation. IXth International Conference on AIDS, Berlin, June 5-11, 1993, PO A14-0283, Abstract Book I: 182.

25. McDougal JS, Mawie A, Cort SP, et al. Cellular tropism of the human retrovirus HTLV III/LAV 1. Role of T-cell activation and expression of T4 antigen. $J$ Immunol 1985; 142: 431-436.

26. Plata F, Autran B, Martins LP, et al. AIDS virus specific cytotoxic T-lymphocytes in lung disorders. Science 1987; 328: 348-351. 